Provided by the author(s) and University of Galway in accordance with publisher policies. Please cite the published version when available.

\begin{tabular}{|c|c|}
\hline Title & Cyclic performance of steel and composite bracing members \\
\hline Author(s) & Broderick, Brian Michael; Goggins, Jamie \\
\hline $\begin{array}{l}\text { Publication } \\
\text { Date }\end{array}$ & 2005 \\
\hline $\begin{array}{l}\text { Publication } \\
\text { Information }\end{array}$ & $\begin{array}{l}\text { Broderick, BM; Goggins, J; Elghazouli, AY (2005) 'Cyclic } \\
\text { performance of steel and composite bracing members'. Journal } \\
\text { Of Constructional Steel Research, } 61 \text { (4):493-514. }\end{array}$ \\
\hline $\begin{array}{l}\text { Link to } \\
\text { publisher's } \\
\text { version }\end{array}$ & http://dx.doi.org/10.1016/j.jcsr.2004.09.006 \\
\hline Item record & http://hdl.handle.net/10379/3686 \\
\hline
\end{tabular}

Some rights reserved. For more information, please see the item record link above. 
Please cite article as: Broderick B.M., Goggins J.M., Elghazouli A.Y. Cyclic performance of steel and composite bracing members. Journal of Constructional Steel Research 61 (2005) 493-514

\title{
Cyclic Performance of Steel and Composite Bracing Members
}

B.M. Broderick ${ }^{\mathrm{a}^{*}}$, J.M. Goggins ${ }^{\mathrm{a}}$, A.Y. Elghazouli ${ }^{\mathrm{b}}$

${ }^{a}$ Dept of Civil, Structural \& Environmental Engineering, Trinity College, Dublin, Ireland.

${ }^{\mathrm{b}}$ Dept of Civil \& Environmental Engineering, Imperial College, London, UK.

\begin{abstract}
This paper describes an experimental study on the response of hollow and filled steel members to monotonic and cyclic axial loading. Monotonic tests were first performed on short specimens to establish their compressive and tensile axial resistances and to investigate the effect of infill on local buckling and ductility. These were followed by cyclic tests on longer bracing members with three different cross-section sizes. The presence of concrete infill was observed to influence the mode of failure displayed by the specimens, as well as their compression and tension load responses. The ductility capacities of the individual specimens are compared, and the effects of slenderness, steel strength and infill are quantified. The experimental findings are compared with the recommendations of a number of international codes of practice and previous research studies on the seismic response of steel braces. It is found that the infill contributes to the compression resistance of the brace, even after multiple inelastic load reversals, and that it can improve ductility capacity by preventing or limiting local buckling.
\end{abstract}

\footnotetext{
* Dr. Brian Broderick, Department of Civil, Structural \& Environmental Engineering, Trinity College, Dublin 2, Ireland. Tel.: +353-1-6082348. Fax:+353-1-6773072. E-mail: bbrodrck@tcd.ie
} 


\section{Keywords}

Bracing members, earthquake resistance, concrete infill, buckling strength, cyclic loading, ductility capacity, post-buckling resistance.

\section{Introduction}

The earthquake resistance of building structures can be effectively provided through the utilisation of braced-frame configurations. Rectangular (RHS) and square (SHS) hollow sections are often employed as bracing members for structural as well as aesthetic reasons. For a severe seismic event, the main design objective is to maintain overall structural integrity without collapse. As part of the capacity design philosophy, energy is dissipated through critical members and components, which are expected to undergo inelastic cyclic deformations without suffering significant loss of strength. Clearly, in the case of braced frames, these critical members are the diagonal braces, for which a detailed assessment of cyclic response is fundamental to the seismic design process.

Compared to other forms of steel member, hollow sections are very effective at resisting axial loads. However, when such sections possess thin walls, they are susceptible to local buckling at high compressive strains. Under cyclic loading, the onset of local buckling reduces the ductility of the brace member and may lead to brittle failure. This has been observed in a number of experimental studies on cold-formed hollow section bracing members (for example, [1] - [4])

It was envisaged that filling hollow steel sections with concrete or mortar would improve their squash load, but more importantly, it would delay the onset of local buckling and improve the member's post-buckling response. In addition, the inherent improvement in fire resistance provided by composite members may also lend this member type as a viable option in practical design situations. 
A large amount of research has been performed into the response of concrete-filled RHS stub columns, such as [5-16]. In summary, it was found that the presence of concrete infill eliminated or delayed local buckling in steel hollow sections, leading to increased ductility. At certain values of longitudinal strain, the infill begins to increase in volume due to microcracking, which induces concrete confinement by the steel tube. The confining pressure is less, and the material degradation greater, for square rather than circular sections. This is because for square columns, the lateral confining pressure is not uniformly applied to the concrete surface. As a result, the concrete core and steel tube are not in firm contact with each other, and local buckling of the tube may take place.

Comparatively less research has been performed on void-filled RHS braces subjected to cyclic axial loading. Earlier experimental work by Liu \& Goel [17] on the cyclic behaviour of cold-formed steel RHS bracing members filled with concrete found that the infill improved specimen buckling, post-buckling and tensile capacity, reduced the severity of local buckling and hence delayed cracking of the steel, and ultimately increased ductility capacity. The presence of concrete infill led to the greatest improvement in performance for specimens with larger width-to-thickness ratios and smaller overall slenderness ratios, as these members are more susceptible to local buckling. It was noted that increasing the strength of the concrete infill over 28MPa and/or using steel fibres did not affect the behaviour of the composite specimens. This was because the specimens were mainly governed by overall and local buckling of the steel tubes.

Liu \& Goel [17] proposed an approximate method to compute the first buckling load based on the separate capacities of the steel tube and concrete, and assuming strain compatibility between the two materials.

Zhao et al [18] tested fixed-ended cold-formed steel rectangular hollow sections filled with normal and lightweight concrete under axial cyclic loading. As expected, it was found that filling the hollow sections increased their first cycle peak load, post peak 
residual strength, ductility and energy absorption capabilities. Similar to Liu \& Goel [17], they found the improvements were more significant in sections with thinner walls, for which the first cycle peak compression loads and the energy dissipated increased by up to $100 \%$ and $85 \%$, respectively. The improvements were also more significant for members filled with normal concrete rather than light-weight concrete.

Zhao et al [18] found good agreement between the first cycle buckling loads of the concrete-filled RHS members and predictions using formulas given in international codes (AISC [19], Eurocode 4 [20], AIJ [21], and CIDECT [22]). This could be expected as the specimens were loaded in compression to at least their expected yield deformation prior to any cyclic loading being applied.

Due to uncertainties related to the actual contribution of the infill during inelastic cyclic response, the use of composite members as dissipative diagonals in concentrically braced frames has not been addressed within the current Eurocode 8 provisions [23]. This paper therefore describes an experimental programme undertaken as part of a wider investigation in support of EC8 development, focusing on the comparative behaviour of hollow and filled bracing members.

Twelve 1100mm long filled and hollow specimens with three different crosssection sizes were tested under cyclic axial displacements of increasing amplitude. In addition, short specimens with a length-to-width ratio of three were tested under displacement-controlled monotonic tension and compression loading. The test set-up, specimen details and material properties are described, and the results are discussed with particular emphasis on differences between the behaviour of the hollow and filled specimens. 


\section{Specimen details and test set-up}

All test specimens comprised rectangular hollow sections (RHS) or square hollow sections (SHS) manufactured from cold-formed steel S235JRH, with a nominal yield strength of $235 \mathrm{~N} / \mathrm{mm}^{2}$ and an ultimate strength of between $360 \mathrm{~N} / \mathrm{mm}^{2}$ and $510 \mathrm{~N} / \mathrm{mm}^{2}$ [24]. The actual material characteristics of the steel specimens were determined from three tensile coupons taken from each length of hollow section, and tested in accordance with the European Standard BS EN 10002-1:2001 [25]. The average measured yield strength of the material was 309.2MPa with a coefficient of variation (COV) of 0.17 . Detailed results and discussion of the material properties of the specimens are presented elsewhere [26].

Three cross-sectional geometries were considered, namely 50x25x2.5RHS, 40x40x2.5SHS and 20x20x2.0SHS. With respect to local buckling, international codes ([19], [27], [28], [29]) classify the walls of these sections as Plastic or Class 1. Such sections should form plastic hinges capable of sustaining the moment capacity at significant levels of rotation. The measured $d / t$ ratios of these specimens are given in Table 1, in which $d$ is defined as by Eurocode 3 [28] as $h-3 t$, where $h$ is the greater overall dimension of the section parallel to the principal axis and $t$ is the wall thickness.

The overall length of the cyclic test specimens $\left(\mathrm{L}_{\mathrm{T}}\right)$ was $1100 \mathrm{~mm}$ with an unstiffened length of $850 \mathrm{~mm}$. This gives a range of normalised slenderness $\bar{\lambda}$ between 0.4 and 1.0, where $\bar{\lambda}$ is defined by Eurocode 3 [28] and Eurocode 4 [20] for non-slender

cross-sections as $\left(\mathrm{N}_{\mathrm{pl}, \mathrm{R}} / \mathrm{N}_{\mathrm{cr}}\right)^{0.5}$, in which $\mathrm{N}_{\mathrm{pl}, \mathrm{R}}$ and $\mathrm{N}_{\mathrm{cr}}$ are the plastic section capacity and theoretical elastic (Euler) buckling load, respectively. Note that Eurocode 4 takes account of the additional strength provided by the concrete $\left(\mathrm{A}_{\mathrm{c}} \mathrm{f}_{\mathrm{ck}}\right)$ in $\mathrm{N}_{\mathrm{pl}, \mathrm{R}}$ and uses an equivalent stiffness (EI) in estimating $\mathrm{N}_{\mathrm{cr}}$.

Twelve cyclic tests were performed in total - six on filled specimens and six on unfilled specimens. Monotonic tensile and compressive tests on short specimens, all with unstiffened length-to-width ratios of three, were also carried out. These included four 
monotonic tension tests and four monotonic compression tests on short 40x40x2.5SHS specimens, in which two tension and two compression specimens were filled with mortar.

In all composite specimens, the hollow steel members were filled with mortar composed of $22.8 \%$ and $77.2 \%$ cement and fine aggregate (sand), respectively, of dry mass and a water/cement ratio of 0.51 . The mix design also contained shrinkage reducing and self-compacting admixtures. The mix was carefully designed to have high strength, low shrinkage and good compaction [30]. Its average compressive and tensile splitting strengths at 28 days were $24 \mathrm{~N} / \mathrm{mm}^{2}$ and $2.53 \mathrm{~N} / \mathrm{mm}^{2}$, respectively.

As shown in Figure 1, fixed end restraints were employed for all test specimens and stiffener plates were placed to provide an adequate length of weld for the required transfer of force between the specimen and the supports, and to encourage uniaxial flexural buckling of the cyclic test specimens. The specimens were manufactured in a rigid jig to ensure that the base plates of the specimens were parallel, the holes aligned properly and all test specimens within each group had the same length.

In the composite specimens, the area surrounding the stiffener was filled with a high-strength glass fibre resin (“Plastic Padding Glass Fibre Resin”). This was activated with approximately 3\% hardener paste (Dibenzoyl Peroxide, paste with plasticizer). The properties of the resin are described in more detail in [26]. The ends of the specimens were then ground flat prior to welding the base plates to the end stiffeners and steel section.

The test machine used for testing the specimens was an RDP hydraulic testing machine, depicted in Figure 2. The frame has four hydraulic locks allowing accurate positioning of the upper loading platen, to which a $500 \mathrm{kN}$ hydraulic actuator is attached, permitting specimens of different lengths to be tested. The same test set-up could therefore be used for both the monotonic and cyclic tests. A more detailed description of the test rig employed is given elsewhere [26]. 
The overall load-displacement response, together with a measurement of the local deformations of the specimens was required in each test. Therefore, a load cell and displacement transducers were employed, as shown in Figure 2. Additionally, longitudinal strain gauges were placed at the centre of each face of the steel section, both at mid-height and close to the stiffener plates at either end.

For the cyclic tests, loading was applied according to the provisions of the ECCS [31]. The recommended complete testing procedure was followed, for which the axial deformation history is shown in Figure 3. This procedure implies applying one displacement cycle at each level of $0.25,0.5,0.75$ and $1.0 \delta_{y}$, followed by 3 cycles at each level of 2, 4, $6 \delta_{\mathrm{y}}$, etc, where $\delta_{\mathrm{y}}$ is the estimated axial yield displacement. The yield displacements measured in the monotonic tensile tests on short specimens were used to determine the amplitudes of the cycles.

\section{Section properties}

Four monotonic compression tests were performed on short 40x40x2.5SHS specimens $\left(\mathrm{L}_{\mathrm{T}}\right.$ $=370 \mathrm{~mm}$ ), two of which were filled with mortar, to investigate the effects of the infill on the local buckling response and the squash load of the section. Similarly, monotonic tensile tests were conducted to investigate the effects of the infill on the ductility and tensile capacity of the section.

Figure 4 compares the compression load-displacement responses of one filled and one unfilled 40x40x2.5SHS specimen. The other specimens displayed very similar responses. To directly compare the influence of the mortar, the load-displacement curves are normalised by the product of the yield strength obtained from the tensile coupon tests $\left(f_{y}\right)$ and the actual cross section area of steel $\left(A_{s}\right)$. From this graph, it is evident that the infill increases the buckling capacity of the strut, but more so its post-buckling. In fact, the maximum compressive resistance of both composite specimens was increased by $26 \%$ due 
to the presence of the mortar. This is notably higher than the Eurocode 4 [20] prediction of 13 percent, which suggests that confinement of the mortar by the steel section significantly increased its compressive resistance (by about $70 \%$ ).

Both inward and outward local buckling were observed in the hollow compression specimens, whereas the mortar in the filled specimens prevented inward local buckling. For both the filled and hollow specimens, local buckling was first observed close to the point when the ultimate resistance of the specimen was attained. The resistances of the specimens reduced after buckling, as indicated in Figure 4.

The load resisted by the steel section alone was evaluated from the average longitudinal strain measured at mid-height and compared with the measured resistance of the overall cross-section. This indicated that filling the hollow section provided a $13 \%$ increase in elastic axial stiffness.

Monotonic tensile tests were performed on twenty-one short hollow specimens of various sizes. The average measured yield and ultimate strengths of the steel sections were 350.2MPa and 394.2MPa, respectively, both with coefficients of variation (COV) of 0.21. The influence of steel tensile strength on the ductility capacities of the monotonic tensile test specimens is displayed in Figure 5. In Figure 5, the material yield strength of the specimens $\left(f_{y}\right)$ has been normalised to the nominal yield strength $\left(f_{y, n o m}\right)$ of S235JRH steel and the ductility capacity is defined as the ratio of elongation at failure $\delta_{\mathrm{u}}$ to the elongation at yield $\delta_{\mathrm{y}}$. Clearly, ductility capacity decreases with increases in steel strength; a reduction attributable to the lower fracture strain of higher strength steels. In Figure 5, a linear regression line is shown that quantifies this relationship, and which is employed later when considering the measured ductility capacities of the cyclic specimens. The results from the tensile tests on 20x20x2.0SHS specimens were omitted from the regression as these specimens failed outside the middle third of the specimen. 
The effect of infill on the behaviour of steel hollow sections in tension was also investigated in monotonic tensile tests. The axial stiffness and resistance of the hollow and filled specimens differed by less than $6 \%$, confirming that the upper-bound tensile capacity of the composite bracing member can be based on that of the bare steel section. As expected, after yielding the filled specimens did not exhibit the necking displayed by the hollow sections. As a result, the ductility capacity of the filled specimens under monotonic tension was on average about 35\% lower than that of the hollow counterparts. Nonetheless, under cyclic loading other parameters also influence ductility capacity, and these are investigated in subsequent parts of this paper.

\section{Cyclic test results}

The measured resistance properties $F_{y}, F_{\max }$, and $F_{c}$ of the cyclic test specimens are summarised in Table 1 , where $\mathrm{F}_{\mathrm{y}}$ is the yield strength of the specimens, $\mathrm{F}_{\max }$ the maximum tensile strength, and $\mathrm{F}_{\mathrm{c}}$ the initial buckling load. Series 1 and 2 refer to hollow and filled specimens, respectively. In both test series, the 20x20x2.0SHS specimens experienced biaxial buckling, while the less slender specimens experienced uniaxial buckling. Typical hysteresis curves obtained from both test series are presented in Figures 6-11, in which the load values are normalised by the yield capacity of the section $\left(f_{y} A_{s}\right)$. All specimens were tested to failure.

In Series 1, the members comprising hollow sections with relatively large width-tothickness ratios (i.e. 40x40x2.5SHS and 50x25x2.5RHS specimens) all experienced inward and outward local buckling in compression (as shown in Figure 12(a)) and necking in tension, whereas the smaller 20x20x2.0SHS specimens experienced necking only. These local phenomena (i.e. local buckling and necking) occurred both at mid-height of the specimens and close to the end stiffeners (Figure 12(b)). Local buckling caused progressive strain localisation that was accentuated with each compressive cycle. When the 
steel was subsequently stretched in tension, small cracks formed at these locations, and repeated cycling eventually caused failure. Fracture occurred at mid-height (as shown in Figure 12(c)), in all specimens except CyIS4-20H which fractured close to an end stiffener. Unlike the equivalent hollow sections, in Series 2 inward local buckling was not observed in the filled 40x40x2.5SHS specimens, as shown in Figure 13. However, both of the filled specimens of this size failed suddenly, in a more brittle manner than the other specimens. The filled 20x20x2.0SHS specimens behaved similarly to the equivalent unfilled specimens, with the exception that the corner on the concave side of the laterally buckled Specimen CyIS3-20F buckled locally outwards at mid-height, while the opposite corner was indented over a height of approximately 40mm. Inward and outward local buckling were observed at mid-height of the filled 50x25x2.5RHS specimens, but this local buckling occurred at larger longitudinal deformations than in the equivalent hollow sections.

\section{Buckling capacity}

In Table 2, the average experimental initial buckling loads for each specimen type $\left(\mathrm{N}_{\text {exp }}\right)$ are compared with unfactored design strengths predicted using European $\left(\mathrm{N}_{\mathrm{EC}}\right)$ (Eurocode 3 [28], Eurocode 4 [20]) and American ( $\left.\mathrm{N}_{\mathrm{AISC}}\right)$ [19] specifications. For cold-formed members, Eurocode 3 allows the use of either the basic material yield strength in conjunction with curve ' $b$ ', or the yield strength from full section tensile tests in combination with curve 'c'. For the 'simplified method of design', Eurocode 4 [20] recommends using design curve 'a' for filled steel hollow sections.

Material properties obtained from the tensile coupon tests were used in conjunction with buckling curves 'a' and 'b' for the filled and hollow specimens, respectively. Good agreement is observed between these design values $\left(\mathrm{N}_{\mathrm{EC} \text {,mat }}\right)$ and those predicted using the American specification $\left(\mathrm{N}_{\mathrm{AISC}}\right)$, all of which underestimate the actual buckling resistance 
of the specimens (Table 2). For comparison, the measured section yield strengths from the tensile tests on short specimens were also used to predict the buckling capacity ( $\left.\mathrm{N}_{\mathrm{EC} \text {,sect }}\right)$ of the filled and hollow specimens using buckling curves 'a' and 'c', respectively. For most specimens, these design values showed better agreement with measured buckling strengths. In fact, the observed buckling capacity is slightly overestimated for the filled 40x40x2.5SHS and 50x25x2.5RHS specimens. It should be noted that factors of safety were omitted when estimating design values.

When designing building to resist static loads, a conservative estimate of member capacity normally represents a safe design value. However, in seismic design, an underestimate of brace resistance could result in under-designed non-dissipative elements such as connections, beams and columns, leading to premature brittle failure and global instability. Therefore, a non-conservative evaluation of the actual buckling strength of brace members is necessary, in which case, predictions based on section strength seem more appropriate, for both filled and hollow specimens.

The actual buckling resistances $\left(\mathrm{N}_{\exp }\right)$ of the brace members lie between $20 \%$ and 81\% of their Euler values $\left(\mathrm{N}_{\mathrm{cr}}\right)$, with closer agreement as brace slenderness increases (Table 2). This provides an indication of the degree of inelastic buckling which occurred. For filled members, an equivalent stiffness $(E I)_{e}$ was used to determine $N_{c r}$, where $(E I)_{e}=$ $E_{a} I_{a}+0.8 E_{c d} I_{c}$ in which $E_{a}$ and $I_{a}$ are the elastic modulus and second moment of area for the considered bending plane of the structural steel, and $0.8 \mathrm{E}_{\mathrm{cd}} \mathrm{I}_{\mathrm{c}}$ is the effective stiffness of the concrete part [20].

In Figure 14, the buckling resistance of each specimen has been normalised by the plastic section capacity $\mathrm{N}_{\mathrm{pl}, \mathrm{R}}$ to allow a direct comparison to be made between the experimental results and those predicted by international standards. The North American standard [19] employs a curve similar to Curve 'b' in Eurocode 3 [28]. These design 
curves predict the buckling resistance well, with curves 'a' and 'c' of Eurocode 3 providing reasonable upper and lower bounds.

\section{Post-buckling compressive strength}

In all tests, once first buckling of the specimens had occurred, their compressive resistance decreased upon applying larger compression deformations or during the second and third cycle at a given displacement amplitude (Figures 6-11). Figures 15 and 16 show the relationship between the compressive strength (normalised using the yield strength determined from the coupon tests) at ductility levels (i.e. $\delta / \delta_{\mathrm{y}}$ ) of 2 and 5 , respectively, and the normalised slenderness $(\bar{\lambda})$. In general, the compressive strength degradation decreases with increasing slenderness. The infill does not appear to greatly improve the post buckling capacity of the specimens at a ductility of 2 (Figure 15), probably because local buckling is not significant at this stage. However, at higher ductility levels local buckling becomes more pronounced in the hollow specimens but is limited somewhat in the filled specimens, thus improving their post-buckling resistance, especially for the stockier specimens (Figure 16).

An accurate estimate of the post-buckling resistance of brace members is important as it can determine the maximum base shear and column loads in some brace configurations [32] and also influences the overall energy dissipation capabilities of the brace member. The experimental results are compared with predictions by Goggins et al [33], Tremblay [4] and Nakashima et al [34] in Figures 15 and 16. These predictions were based on non-linear regression of results data from cyclic tests on bare steel specimens. The predictions are in general agreement with the observed experimental responses of the steel hollow specimens tested in this study. However, they slightly underestimate the postbuckling resistance of the filled specimens, in particular during the first cycle at higher ductility levels. On the other hand, the American seismic provision [27] assumes that the 
post-buckling brace capacity is $0.26 \mathrm{P}_{\mathrm{n}}$, where $\mathrm{P}_{\mathrm{n}}$ is the predicted maximum axial compression strength, regardless of the ductility level. This provides a good lower bound for the compressive strength of both filled and hollow specimens at a ductility of 5 (Figure 16), but significantly underestimates their compressive strength at a ductility of 2 (Figure 15).

\section{Cyclic tension loads}

As observed in previous studies ([1], [2], [18], [30]), the cyclic loading procedure employed has a direct influence on the response of brace specimens, which is also indicated in Figures 6-11. Beyond the elastic phase, during the first cycle at a new displacement amplitude, both hollow and filled specimens stretch inelastically, causing a permanent elongation. When the member is subsequently compressed, a lateral deflection occurs. Because the strut had lengthened in tension, a residual lateral deformation is still present when the specimen subsequently unloads to its starting point of zero axial displacement. Thus, the beginning of the positive displacement phase of each cycle involves straightening the strut. Generally, specimens do not return to being fully straight until the maximum amplitude of positive displacement is reached. This behaviour accounts for the apparent reductions in brace stiffness and maximum tension load displayed in the later cycles of the hysteresis curves.

Figures 17(a) and (b) show typical normalised envelopes for the tension side, obtained from the hysteresis curves for cycle 1 and 3, respectively. Very good agreement is observed between the response of the hollow and filled specimens, with the exception that the normalised tensile capacity of the $40 \times 40 \times 2.5 S H S$ is greater for the filled specimen. Figure 18 shows the peak tensile loads at a ductility of 5 plotted against normalised slenderness. The more slender specimens are seen to suffer the greater reduction in peak tensile loads. 


\section{Ductility and energy dissipation}

The ductility capacities of the brace specimens are plotted against member and section slenderness in Figures 19 and 20, respectively. The influence of material strength on ductility capacity has been taken into account by employing the actual yield strength $f_{y}$ of each individual specimen and the slope of the regression relationship shown in Figure 5.

The ductility capacity of both hollow and filled specimens increases with member slenderness (Figure 19). This trend has been observed in previous studies on bare steel members ([2], [4], [33]). The variation of ductility capacity with section width-to-thickness (d/t) ratio does not show a clear trend (Figure 20). The ductility capacities of the $50 \times 25 \times 2.5 R H S$ specimens $(d / t=17.1)$ are higher than those of the $40 \times 40 \times 2.5 S H S$ specimens $(d / t=13.1)$ because the stiffer webs of the rectangular section improve the local buckling resistance of the flanges. The influence of the relative stiffness of adjacent walls of rectangular sections has also been noted in previous tests on hollow specimens [35].

The influence of the infill on ductility is observable in Figures 19 and 20, with the filled specimens generally displaying higher capacities. No improvement is observed for the most slender specimens because local buckling did not occur due to their low section slenderness (Figure 20). In addition, these specimens have higher member slenderness, resulting in their buckling behaviour being dominated more by elastic response rather than plastic response, as is the case for stockier specimens.

Although ductility capacity under monotonic tension may be lower for the filled members (see section “Section properties”), the situation is different under cyclic loading. In this case, local buckling plays a more significant role in initiating and determining failure. Hence, since the infill delays local buckling, it also provides relatively higher ductility. Clearly, this would only be useful for members with relatively low overall slenderness, or relatively high $\mathrm{d} / \mathrm{t}$, or both. On the other hand, if $\mathrm{d} / \mathrm{t}$ is low (e.g. $<<10$ ) 
particularly when the overall slenderness is high, the infill would not make a positive contribution to seismic behaviour, and may in fact result in inferior performance since failure becomes more dominated by steel fracture in tension (rather than due to the cracks initiated at the local buckling regions).

Overall, the slopes of the regression lines shown in Figures 19 and 20 indicate that the ductility capacity of filled members is less sensitive to member and section slenderness than that of hollow specimens. However, assessment of the amount of energy dissipated by brace specimens indicated no significant difference between hollow and filled members. On the other hand, the amount of energy dissipated by both filled and hollow specimens decreased with increase in slenderness.

\section{Conclusions}

An experimental study has been described in which the response of hollow and filled coldformed hollow steel bracing members to cyclic loading was investigated.

The observed experimental bucking capacities of both hollow and filled specimens agreed well with the values employed in European and American design codes. This implies that cyclic loading did not affect the contribution made by the infill to the compression resistances of the composite struts. Moreover, at relatively high ductility levels, the post-buckling compression resistances of the filled specimens was noticeably higher than those of the equivalent hollow specimens, confirming that the infill continued to enhance brace strength at larger displacements. On the other hand, the tension load response envelopes of the hollow and filled specimens were similar.

Predictions based on buckling curves ' $a$ ' and 'c' in Eurocode 3 for filled and hollow specimens, respectively, in conjunction with the actual section strength gave the closest approximation to the observed buckling capacities of the brace members. In contrast, predictions based on measured material strengths under predicted the 
experimental values by up to $27 \%$, which in seismic design could lead to an underestimate of design base shear. For composite members, the section resistance approach slightly overestimated the buckling resistance of most specimens, and hence represents the upper bound required in capacity design. For the hollow specimens, a similar upper bound could be achieved by employing curve 'b' with section, rather than material, strength.

At low ductility demand levels, the post-buckling compression resistance of a brace can influence the maximum seismic forces acting on the braced frame, while at high ductility levels, it affects the axial compression forces in column members. A design rule in the American seismic provision [27] appears to provide a safe value when considering the latter issue, but it grossly underestimates the resistance at low ductility levels. At low slenderness, the normalised post-buckling resistances of filled specimens were greater than those of hollow specimens, implying that relationships proposed in previous studies on steel struts ([4], [33] and [34]) may underestimate the resistance of composite braces.

To prevent inadvertent yielding in non-dissipative parts of the structure, an accurate estimate of the ultimate tensile capacity of brace members is essential. The ultimate resistance of all cyclic test specimens exceeded the yield strengths of the cross-section by at least 20\%. Moreover, in both monotonic and cyclic tests, this margin was always slightly greater for the composite specimens. Hence, additional caution, expressed in terms of the overstrength factor employed, should be exercised if the design tension capacity of a filled brace is based on the resistance of the steel section only. This issue has received relatively little previous attention, and is worthy of further study.

The ductility capacities of both hollow and filled specimens were observed to be proportional to their overall slenderness, and inversely proportional to their section slenderness and yield strength. In comparing the performance of hollow and filled specimens, it is evident that the mortar infill prevented inward local buckling in most cases, and delayed it in others. This in turn meant that when allowance was made for the 
different yield strengths of the individual specimens, the infill was observed to improve ductility capacity, especially at low slenderness values. Generally, the presence of infill reduced the sensitivity of the ductility capacity to member and section slenderness. However, no consistent differences in the energy dissipation capabilities of the hollow and filled specimens were observed.

\section{Acknowledgements}

The second author wishes to acknowledge the financial support of the Trinity Trust and Enterprise Ireland through the Ussher Fellowship and Student sponsorship no. BR/2000/056, respectively. The work described in this paper was carried out with the help of the technical staff of the structures laboratory at Trinity College Dublin.

\section{References}

[1] Popov E.P., Zayas V.A., Mahin S.A. 'Cyclic inelastic buckling of thin tubular columns’. Journal of the Structural Division, ASCE, 105(ST11), 1979; 2261-2277.

[2] Jain A.K., Goel S.C., Hanson R.D. 'Hysteretic cycles of axially loaded steel members'. Journal of the Structural Division, ASCE, 106(ST8), 1980; 1777-1795.

[3] Elchalakani, M., Zhao, X.-L., Grzebieta, R. 'Tests on cold-formed circular tubular braces under cyclic axial loading'. Journal of Structural Engineering, ASCE, 129(ST4), 2003; 507-514.

[4] Tremblay R. 'Inelastic seismic response of steel bracing members'. Journal of Constructional Steel Research, 58 (2002); 665-701.

[5] Furlong R.W. 'Strength of steel-encased concrete beam-columns', Journal of Structural Engineering, ASCE, 93(ST5), 1967; 113-124.

[6] Ge H. B. and Usami T. 'Cyclic tests of concrete filled steel box columns', Journal of Structural Engineering, ASCE, Vol. 122, No. 10, 1996; 1169-1177. 
[7] Bridge R. Q. and O’Shea M. D. 'Behaviour of thin-walled steel box sections with or without internal restraint', Journal of Constructional Steel Research, 47 (1-2), 1998; 73-91. [8] Schneider S. P. 'Axially loaded concrete-filled steel tubes', Journal of Structural Engineering, ASCE, Vol. 124, No. 10, 1998; 1125-1138.

[9] Kitada T. 'Ultimate strength and ductility of state-of-the-art concrete-filled steel bridge piers in Japan’, Engineering Structures, 20 (4-6), 1998; 347-354.

[10] Zhang W. Z. and Shahrooz B. M. 'Comparison between ACI and AISC for concretefilled tubular columns', Journal of Structural Engineering, ASCE, Vol. 125, No. 11, 1999; 1213-1223.

[11] Uy B. 'Strength of concrete filled steel box columns incorporating local buckling', Journal of Structural Engineering, ASCE, Vol. 126, No. 3, 2000; 341-352.

[12] Vrcelj Z. and Uy B. 'Strength of Slender Concrete-filled Steel Box Columns Incorporating Local Buckling', Journal of Constructional Steel Research, 58 (2002); 275300.

[13] Han L. -H. 'Tests on Stub Columns of Concrete-Filled RHS Sections', Journal of Constructional Steel Research, 58 (2002); 353-372.

[14] Han L. -H. and Yao G.-H. 'Behaviour of concrete-filled hollow structural steel (HSS) columns with pre-load on the steel tubes', Journal of Constructional Steel Research, 59 (2003); 1455-1475.

[15] Liu D., Gho W. -M., Yuan J. 'Ultimate capacity of high-strength rectangular concretefilled steel hollow section stub', Journal of Constructional Steel Research, 59 (2003); 1499-1515.

[16] Hajjar J. F., Gourley B. C., Olson M. 'A cyclic nonlinear model for concrete-filled tubes. II Verification.', Journal of Structural Engineering, ASCE, Vol. 123, No. 6, June 1, 1997; 745-754. 
[17] Liu Z. and Goel S. C. 'Cyclic load behavior of concrete-filled tubular braces’, Journal of Structural Engineering, ASCE, 114 (7), 1988; 1488-1506.

[18] Zhao X.-L., Grzebieta R., Lee C. 'Void-Filled Cold-Formed Rectangular Hollow Section Braces Subjected to Large Deformation Cyclic Axial Loading', Journal of Structural Engineering, ASCE, Vol. 128, No. 6, June 1, 2002; 746-753.

[19] AISC. 'Load and Resistance Factor Design Specification for structural steel buildings’. American Institute of Steel Construction, Inc., Chicago, IL, 1999.

[20] CEN. ENV 1994-1-1. Eurocode 4: 'Design of Composite Steel and Concrete Structures - Part 1-1: General Rules and Rules for Buildings’, 1993.

[21] Architectural Institute of Japan (AIJ). 'Standard for structural calculations of steelreinforced concrete structures', $4^{\text {th }}$ Ed., Tokyo, 1987.

[22] Bergmann R., Matsui C., Meinsma C., Dutta D. 'Design guide for concrete-filled hollow section columns under static and seismic loading', CIDECT, TÜV-Verlag GmbH, Köln, Germany, 1995.

[23] CEN. prEN 1998-1. 'Eurocode 8: Design provisions for earthquake resistance of structures - Part 1-1: General rules, seismic actions and general requirements for structures’, Draft No. 4, December 2001.

[24] British Standards Institute. BS EN 10219-1:1997. 'Cold formed structural hollow sections of non-alloy and fine grain structural steels'. Technical delivery requirements. BSI, London, 1997.

[25] British Standards Institute. BS EN 10002-1:2001. 'Metallic materials - Tensile testing - Part 1: Method of test at ambient temperature'. BSI, London, 2001.

[26] Goggins J.M. 'Earthquake resistant hollow and filled steel braces'. PhD Thesis. Trinity College, University of Dublin; In preparation.

[27] AISC. 'Seismic Provisions for Structural Steel Buildings', American Institute of Steel Construction, Inc., Chicago, IL, May 2002. 
[28] CEN. ENV 1993-1-1. Eurocode 3: 'Design of Steel Structures - Part 1-1: General Rules and Rules for Buildings'. 'Part 1.3: General rules - Supplementary Rules for Coldformed Thin Gauge Members and Sheeting’, 1996.

[29] British Standards Institute. BS 5950-1. 'Structural use of steelwork in building - code of practice for design. Rolled and welded sections’. BSI, London, 2000.

[30] Goggins J. and Broderick B.M. 'The determination of a suitable mortar mix design to fill slender hollow sections', In Proceedings of Colloquium on Concrete Research in Ireland, Belfast, P.A.M. Basheer \& M.I. Russell (editors), The Queen's University of Belfast, 2003; 107-116.

[31] 'ECCS - Technical Committee 1 - Structural Safety and Loadings - Technical Working Group 1.3 - Seismic Design Recommended Testing Procedure for Assessing the Behaviour of Structural Steel Elements under Cyclic Loads’, 1st Edition, Brussels, 1986. [32] Elghazouli, A.Y. 'Seismic design procedures for concentrically based frames'. Proc Inst Civil Engnrs Struct and Build, 156 (2003); 381-394.

[33] Goggins J. M., Broderick B. M., Elghazouli, A. Y., Lucas A. S. ‘Experimental cyclic response of cold-formed hollow steel bracing members'. Submitted to Engineering Structures.

[34] Nakashima M., Nishino T., Tsuji B., Iwasa Y. 'Effect of strain hardening on postbuckling resistance of steel braces’. In: Proc. of Third Pacific Structural Steel Conference, Tokyo, Japan, 1992; 561-568.

[35] Wilkinson T. and Hancock G.J. 'Tests to Examine Compact Web Slenderness of Cold-Formed RHS’, Journal of Structural Engineering, ASCE, Vol. 124, No. 10, October, 1998; 297-305. 

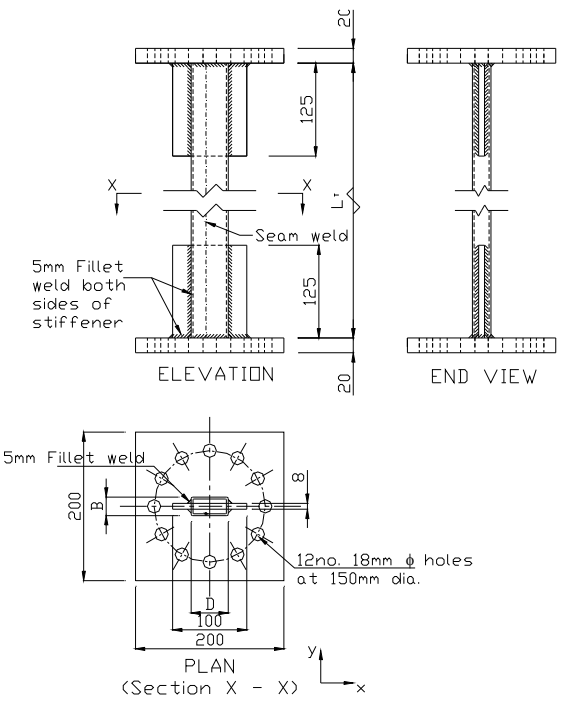

Figure 1. Test specimen.

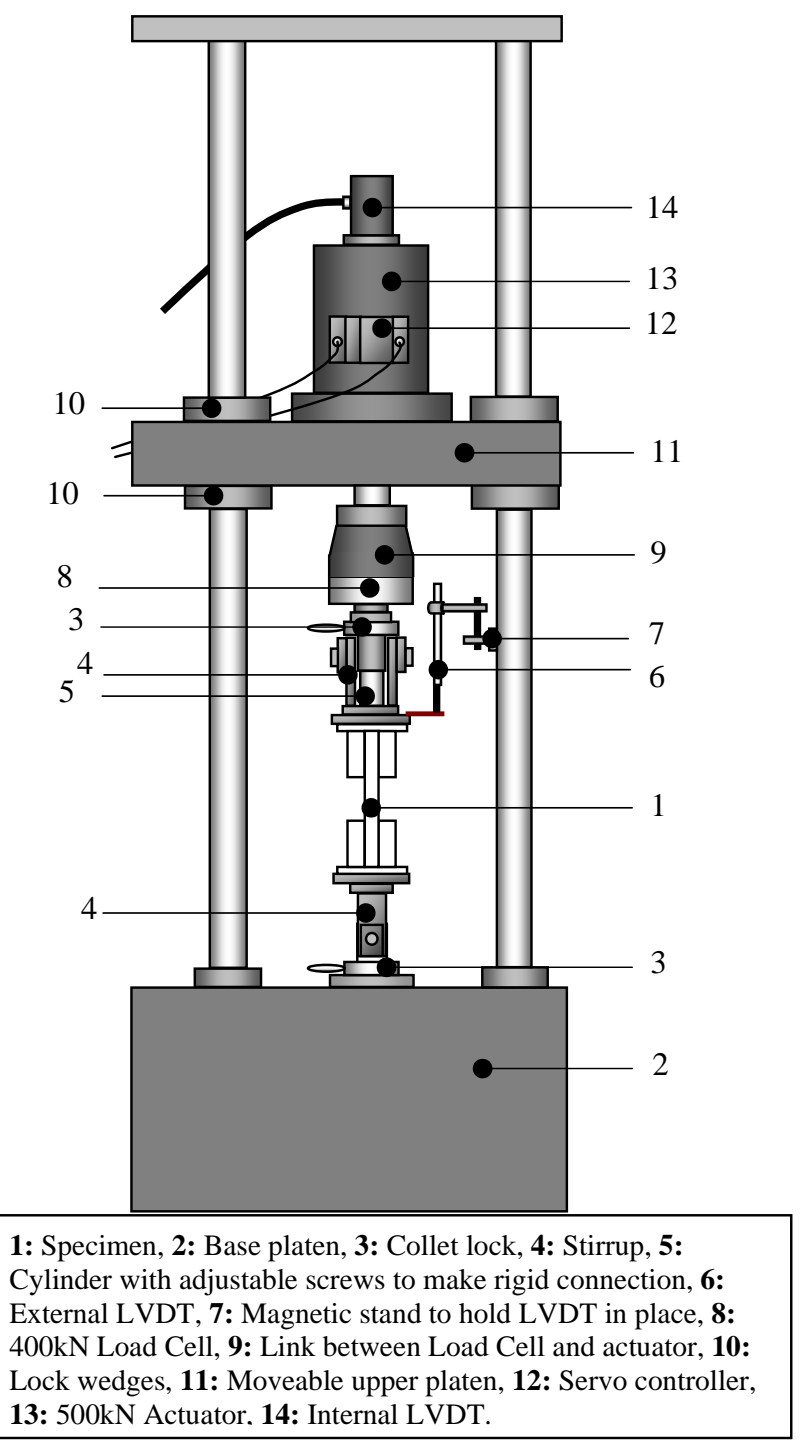

Figure 2. Test set-up. 


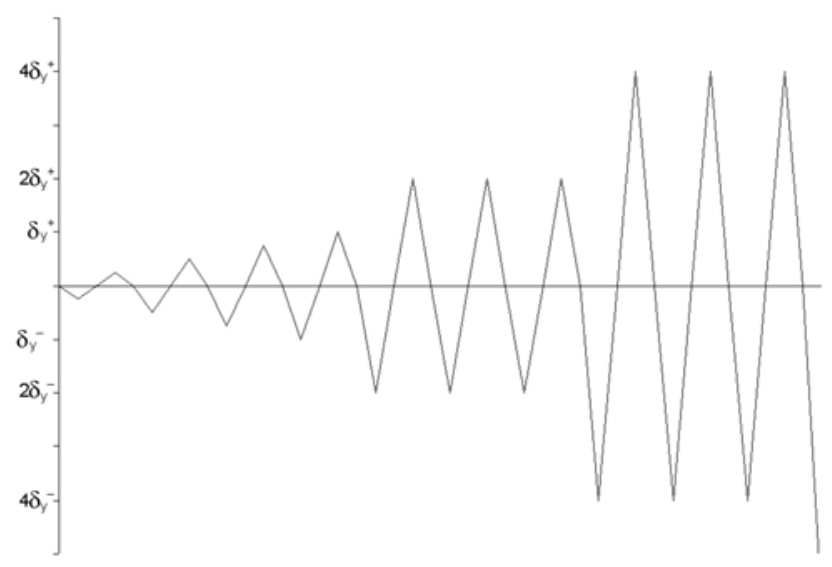

Figure 3. Cyclic displacement waveform for ECCS procedure.

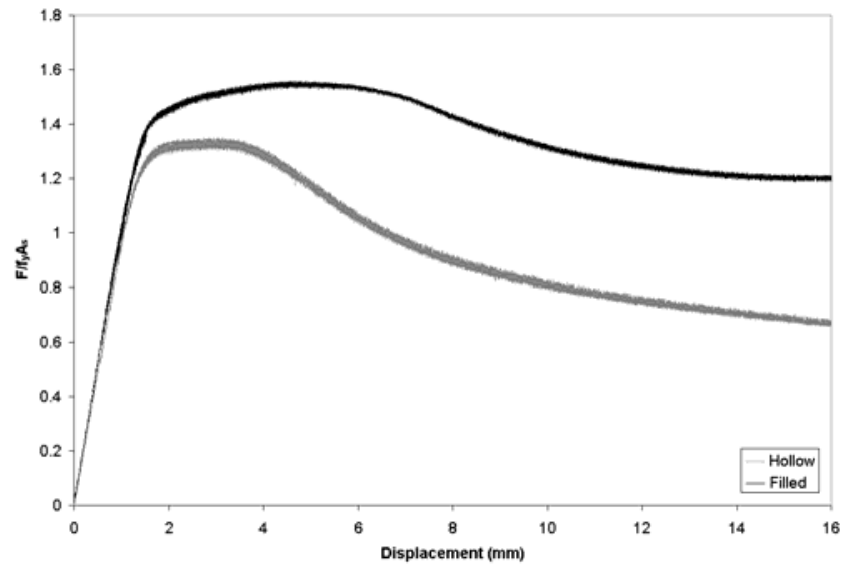

Figure 4. Monotonic compression load-displacement curves.

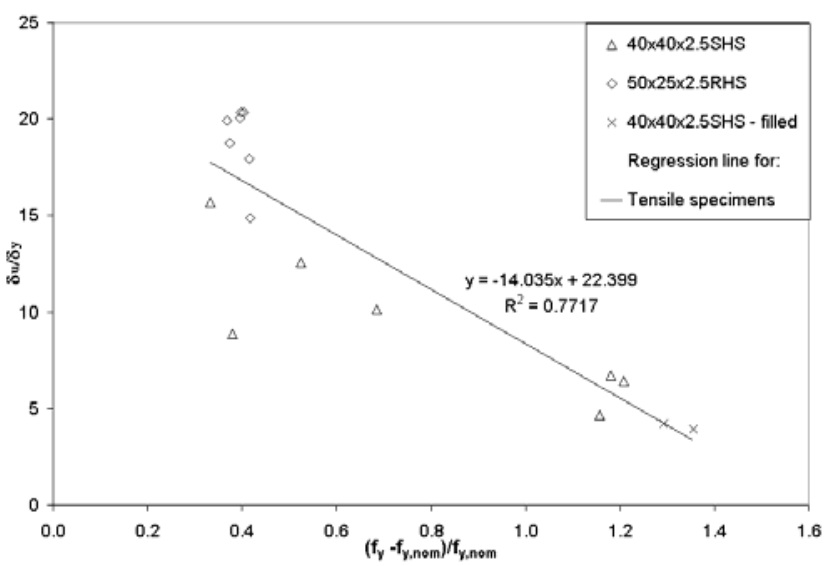

Figure 5. Ductility versus normalised yield strength. 


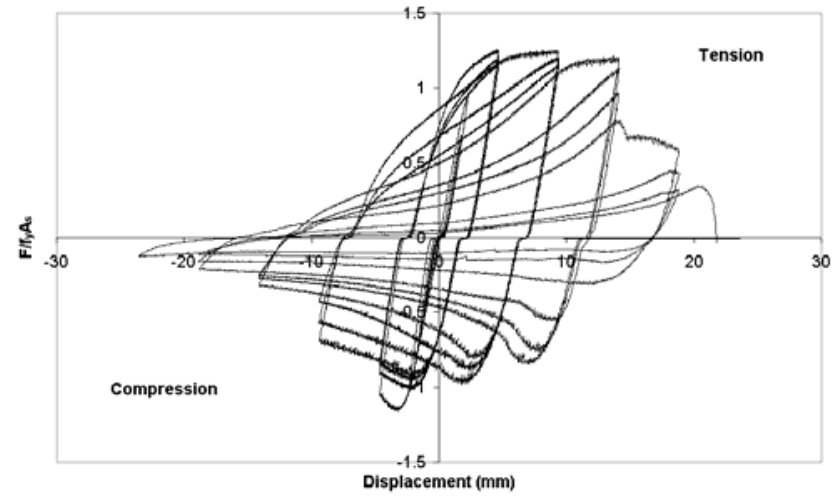

Figure 6. Experimental load-displacement response of hollow specimen CyIS1-40H (40x40x2.5SHS).

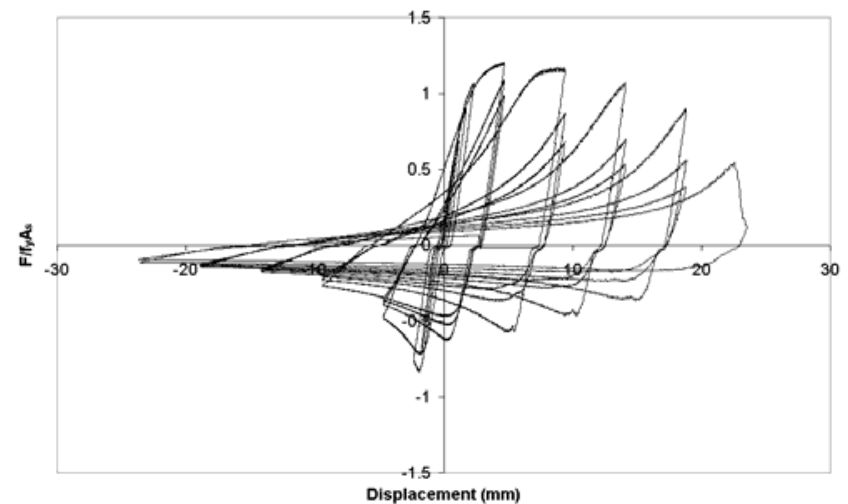

Figure 7. Experimental load-displacement response of hollow specimen CyIS4-20H (20x20x2.0SHS).

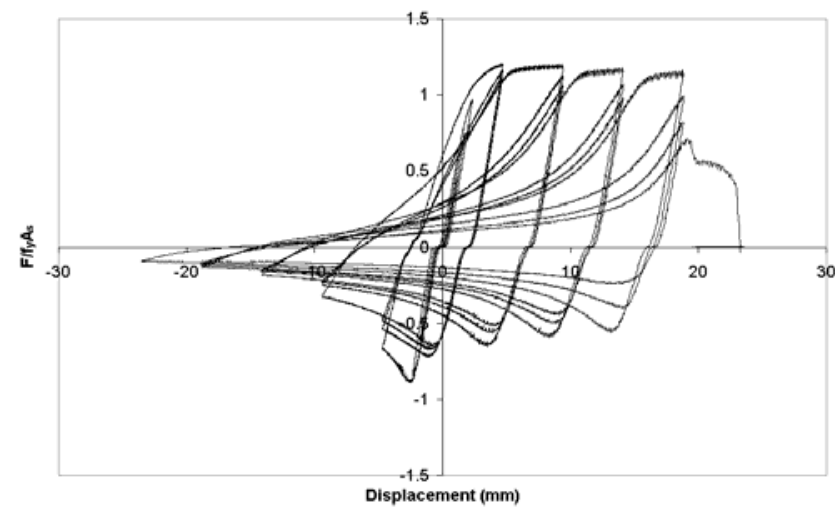

Figure 8. Experimental load-displacement response of hollow specimen CyIS5-50H (50x25x2.5RHS). 


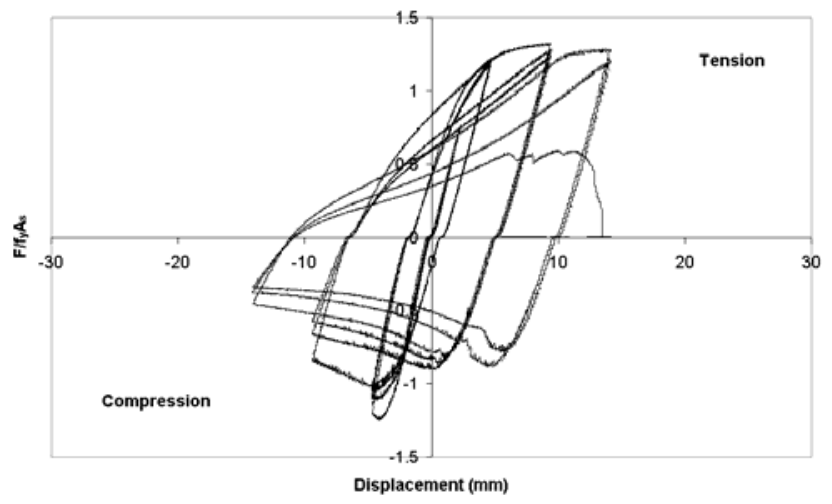

Figure 9. Experimental load-displacement response of filled specimen CyIS1-40F (40x40x2.5SHS).

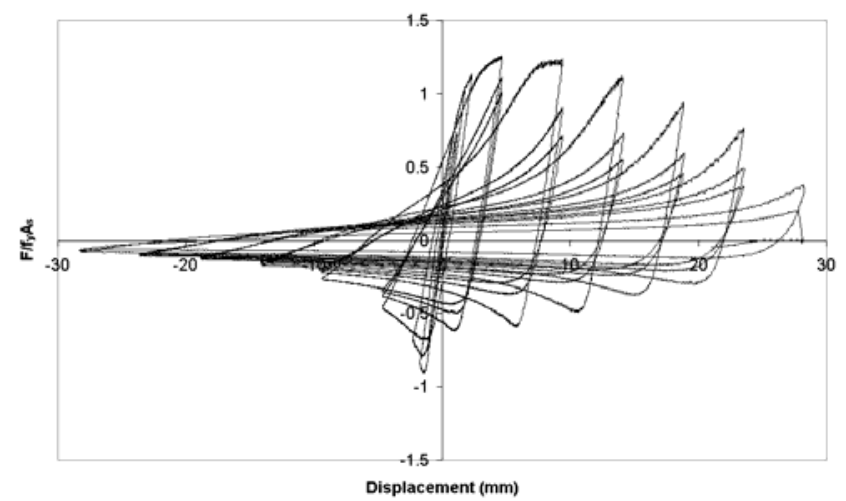

Figure 10. Experimental load-displacement response of filled specimen CyIS3-20F (20x20x2.0SHS).

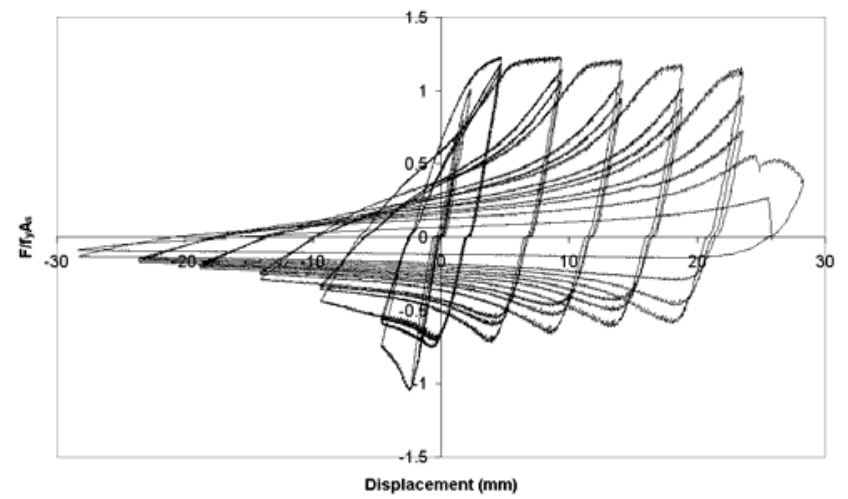

Figure 11. Experimental load-displacement response of filled specimen CyIS5-50F (50x25x2.5RHS). 


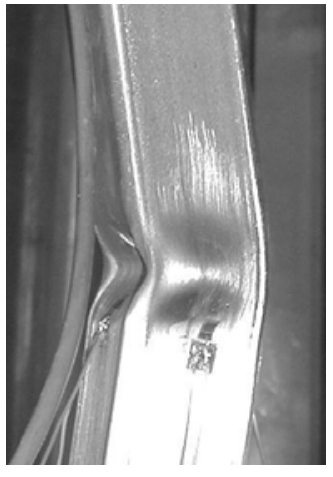

Figure 12 (a). Local buckling of 40x40x2.5SHS hollow specimen CyIS2-40H.

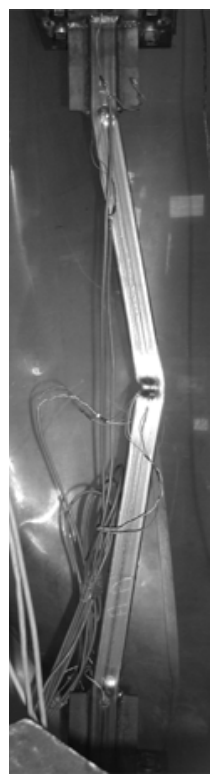

Figure 12 (b). Local and overall buckling of 40x40x2.5SHS hollow specimen CyIS2-40H.

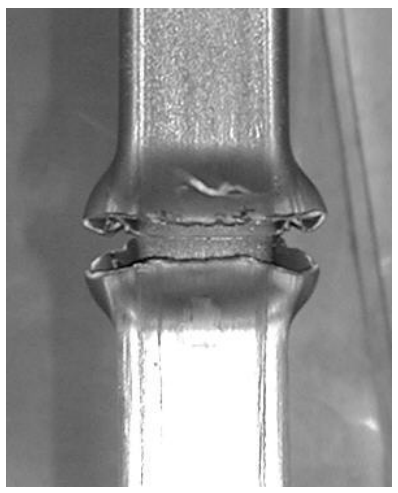

Figure 12 (c). Fracture at mid-height of 40x40x2.5SHS hollow specimen CyIS2-40H. 


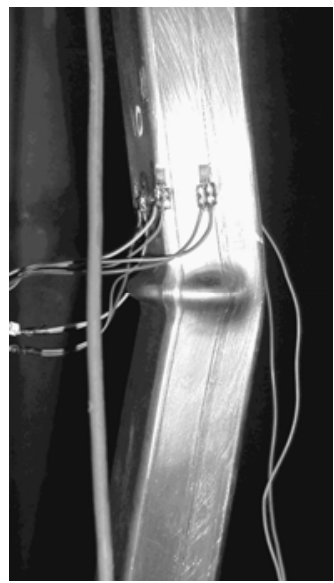

Figure 13. Local buckling of 40x40x2.5SHS filled specimen CyIS1-40F.

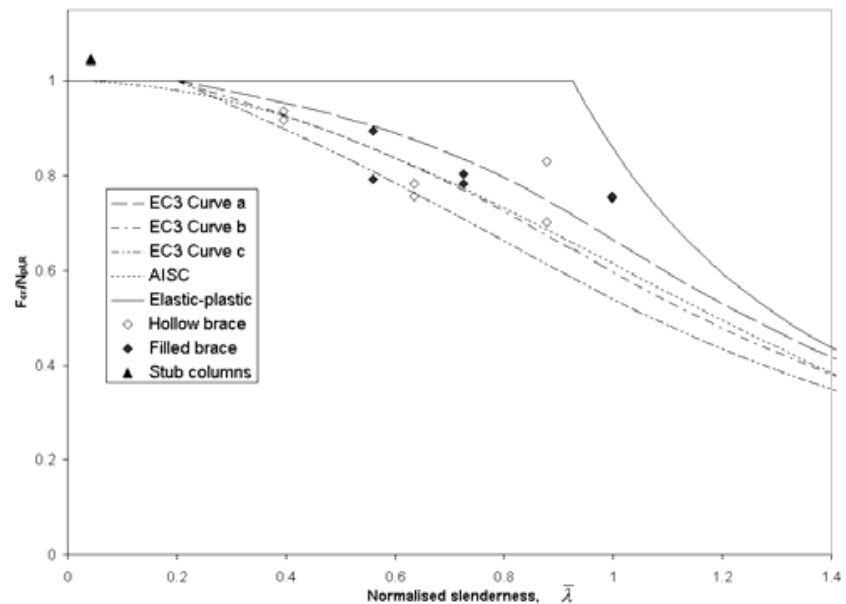

Figure 14. Normalised buckling loads. 


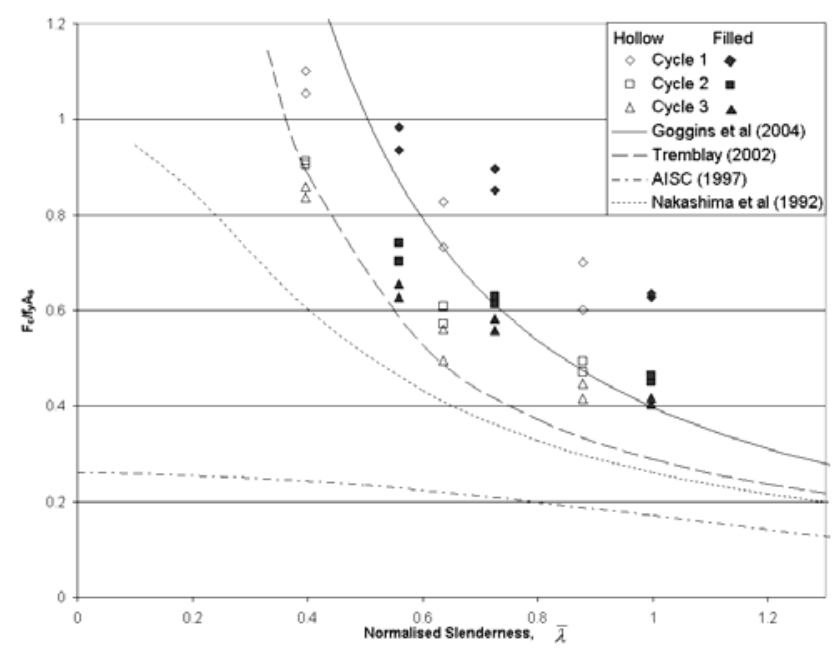

Figure 15. Normalised compressive strength versus slenderness at ductility level of 2.

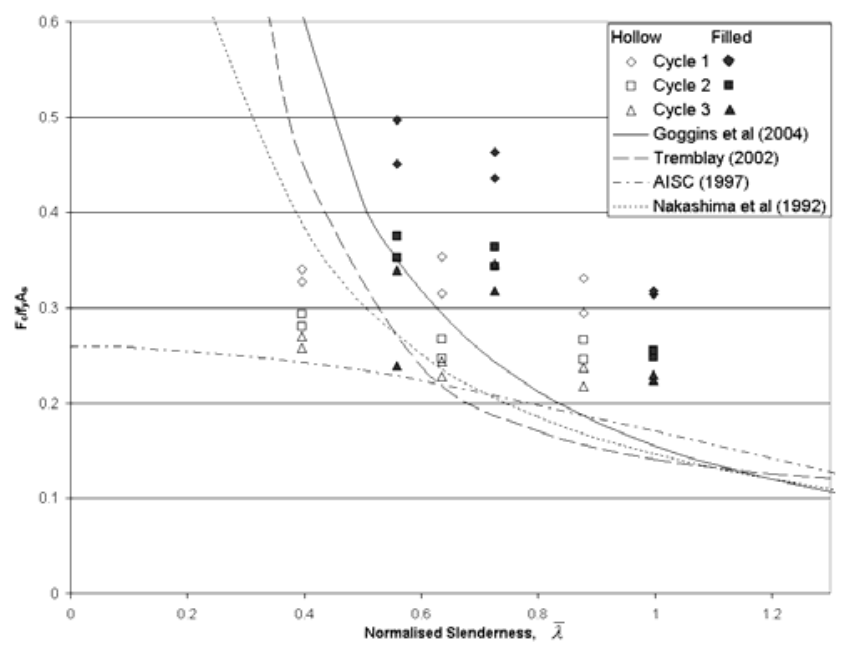

Figure 16. Normalised compressive strength versus slenderness at ductility level of 5. 


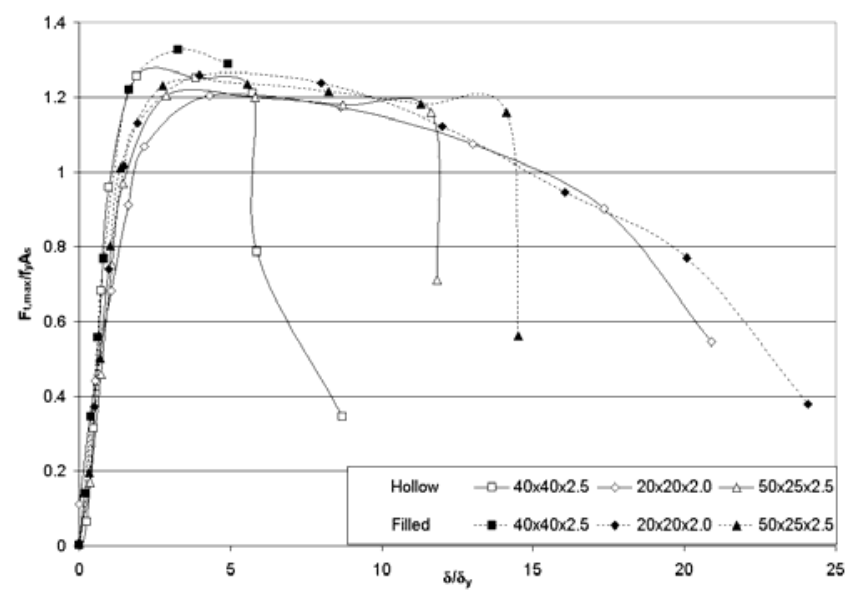

Figure 17 (a). Tensile envelope curves for specimens in $1^{\text {st }}$ cycle.

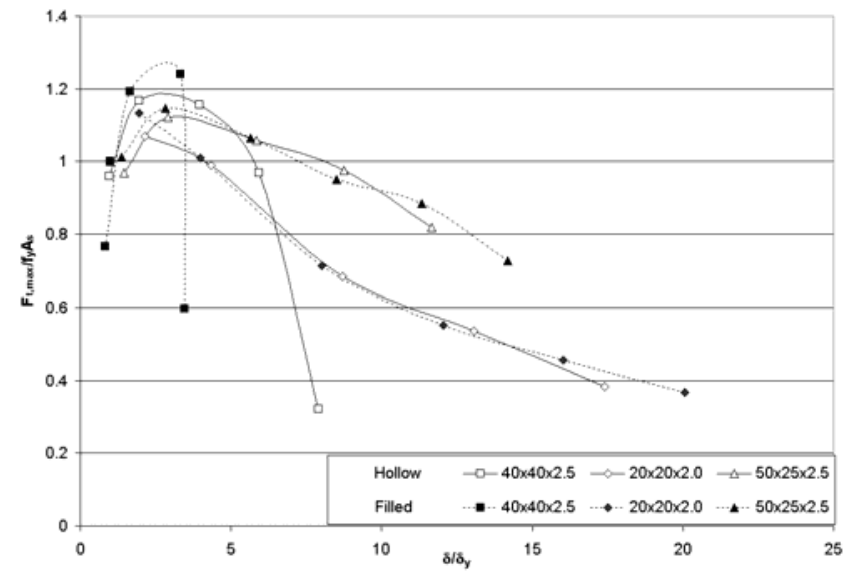

Figure 17 (b). Tensile envelope curves for specimens in $3^{\text {rd }}$ cycles.

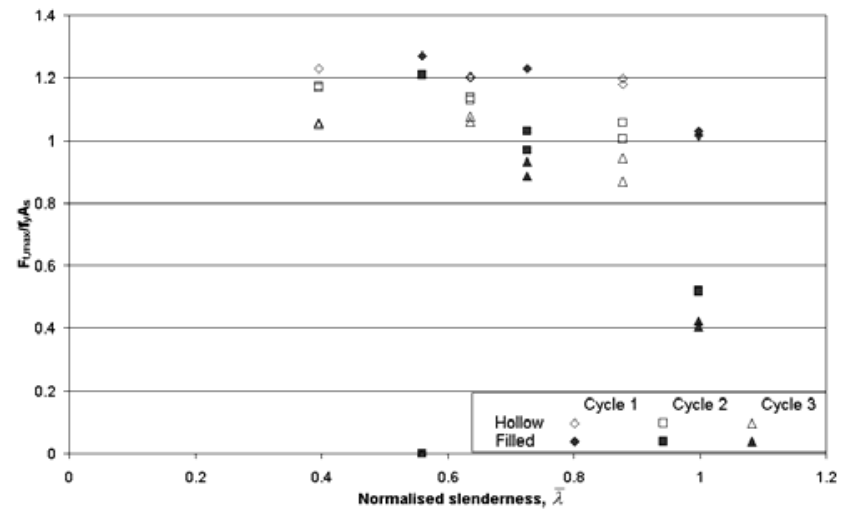

Figure 18. Peak tensile loads at a ductility of 5.0. 


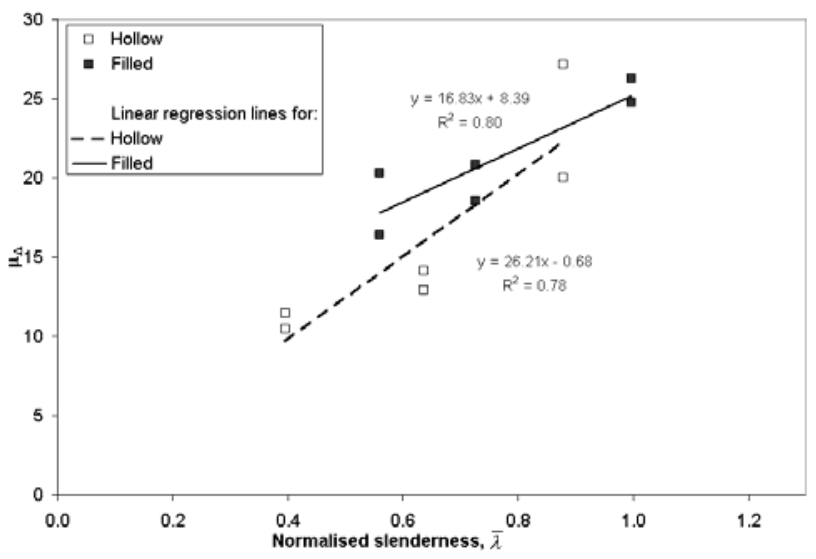

Figure 19. Ductility capacity versus member slenderness.

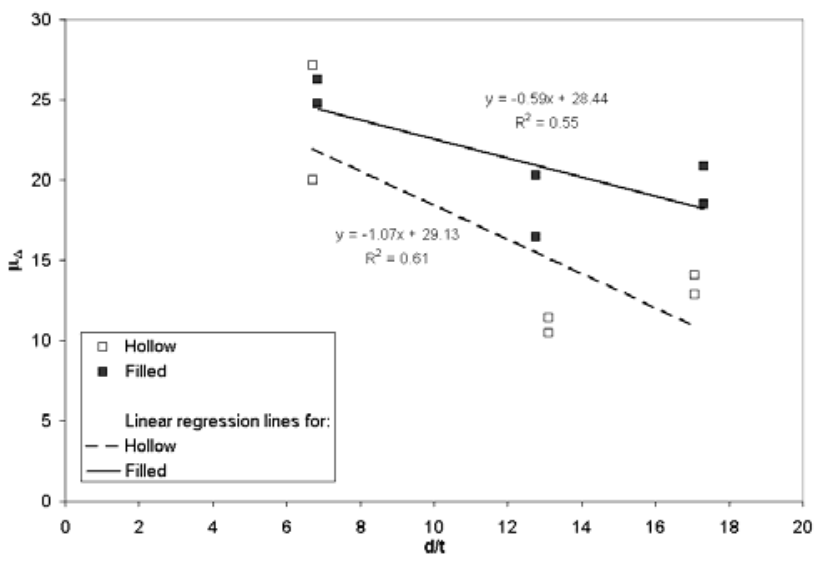

Figure 20. Ductility capacity versus section slenderness. 
Table 1. Cyclic test programme and specimen resistances.

\begin{tabular}{lllllll}
\hline $\begin{array}{l}\text { Test } \\
\text { ID }\end{array}$ & $\begin{array}{l}\text { Section } \\
\text { Size }\end{array}$ & $\lambda$ & $d / t$ & $\begin{array}{l}\mathrm{F}_{\mathrm{y}} \\
(\mathrm{kN})\end{array}$ & $\begin{array}{l}\mathrm{F}_{\max } \\
(\mathrm{kN})\end{array}$ & $\begin{array}{l}\mathrm{F}_{\mathrm{c}} \\
(\mathrm{kN})\end{array}$ \\
\hline Series1 & (Hollow) & & & & & \\
Cy1-40H & 40x40x2.5 & 0.40 & 13.1 & 100.4 & 112.9 & 104.3 \\
Cy2-40H & 40x40x2.5 & 0.40 & 13.1 & 101.5 & 112.4 & 106.6 \\
Cy3-20H & 20x20x2.0 & 0.88 & 6.7 & 26.0 & 45.4 & 27.0 \\
Cy4-20H & 20x20x2.0 & 0.88 & 6.7 & 29.8 & 46.0 & 31.9 \\
Cy5-50H & 50x25x2.5 & 0.64 & 17.1 & 78.1 & 111.5 & 82.3 \\
Cy6-50H & 50x25x2.5 & 0.64 & 17.1 & 83.1 & 111.5 & 85.1 \\
Series2 & (Filled) & & & & & \\
Cy1-40F & 40x40x2.5 & 0.56 & 12.8 & 181.2 & 202.2 & 190.1 \\
Cy2-40F & 40x40x2.5 & 0.56 & 12.8 & 162.3 & 202.2 & 168.5 \\
Cy3-20F & 20x20x2.0 & 1.00 & 6.8 & 37.0 & 52.5 & 37.9 \\
Cy4-20F & 20x20x2.0 & 1.00 & 6.8 & 36.7 & 52.4 & 38.1 \\
Cy5-50F & 50x25x2.5 & 0.73 & 17.3 & 95.7 & 118.2 & 100.1 \\
Cy6-50F & 50x25x2.5 & 0.73 & 17.3 & 98.6 & 119.0 & 102.8 \\
\hline
\end{tabular}

Table 2. Average buckling loads for cyclic hollow and filled specimens.

\begin{tabular}{|c|c|c|c|c|c|c|}
\hline $\begin{array}{l}\text { Section } \\
\text { Size }\end{array}$ & $\bar{\lambda}$ & $\begin{array}{l}\text { Test } \\
\left(\mathrm{N}_{\exp }\right)\end{array}$ & $\begin{array}{l}\mathrm{N}_{\exp }{ }^{1)} \\
/ \mathrm{N}_{\mathrm{EC} \text {,mat }}\end{array}$ & $\begin{array}{l}\left.\mathrm{N}_{\exp }{ }^{2}\right) \\
/ \mathrm{N}_{\mathrm{EC} \text {,sect }}\end{array}$ & $\begin{array}{l}\mathrm{N}_{\exp } \\
/ \mathrm{N}_{\text {AISC }}\end{array}$ & $\begin{array}{l}\mathrm{N}_{\text {exp }} \\
/ \mathrm{N}_{\text {Euler }}\end{array}$ \\
\hline \multicolumn{7}{|c|}{ Series 1 (Hollow) } \\
\hline $40 \times 40 \times 2.5$ & 0.40 & 105.5 & 1.27 & 1.03 & 1.27 & 0.21 \\
\hline $20 \times 20 \times 2.0$ & 0.88 & 29.5 & 1.14 & 1.25 & 1.12 & 0.66 \\
\hline $50 \times 25 \times 2.5$ & 0.64 & 83.7 & 1.10 & 1.01 & 1.10 & 0.41 \\
\hline \multicolumn{7}{|c|}{ Series 2 (Filled) } \\
\hline $40 \times 40 \times 2.5$ & 0.56 & 179.3 & 1.12 & 0.93 & 1.15 & 0.32 \\
\hline $20 \times 20 \times 2.0$ & 1.00 & 38.0 & 1.22 & 1.13 & 1.25 & 0.81 \\
\hline $50 \times 25 \times 2.5$ & 0.73 & 101.5 & 1.07 & 0.95 & 1.10 & 0.47 \\
\hline
\end{tabular}

${ }^{1)} \mathrm{N}_{\mathrm{EC} \text {,mat }}$ values are calculated using the measured material strength and buckling curves $\mathrm{a}$ and $\mathrm{b}$ for the filled and unfilled sections, respectively.

${ }^{2)} \mathrm{N}_{\mathrm{EC} \text {,sect }}$ values are calculated using the measured section yield strength from tensile tests on short specimens and buckling curves a and c for filled and unfilled specimens, respectively. 